\title{
Health and Safety in Construction Field: A Bibliometric Analysis From 1964 - 2019
}

\author{
Abdullah Alabdali \\ Associate Dean, Clinical Affairs, Assistant Professor, Program Director, Emergency Medical Services Department, \\ College of Applied Medical Sciences, King Saud Bin Abdulaziz University for Health Sciences, King Abdullah \\ International Medical Research Center, Ministry of National Guard Health Affairs Riyadh. Kingdom of Saudi \\ Arabia
}

\begin{abstract}
To observe and evaluate, the contribution of authors and collaboration of institutes in research productivity in field of Health and Safety in Construction, published in journals indexed in Scopus-Elsevier database from 1964 - 2019. The research data such as publication year, document type, authorship pattern, title, language, subject area, geographical location and keywords on file format with comma-separated value (CSV) techniques used, downloaded on the date June 6, 2020 for tabulations in MS Office Excel Sheet 2010 for bibliometric analysis. A total 6821 documents retrieved from Scopus-Elsevier database with an average of 121.8\% documents during the 56 years. These years divided into four groups and there is a huge comparison found in publications by the first group existing years 2006 - 2019 published 5256, 77\% documents, remaining 1565, 23\% literature published in 42 years. Articles 4042, 59.2\% in form of document got first place, followed by Conference Papers 1890, 27.7\%, and Review Articles 467, 6.8\% out of 6821 documents. Ten journals associate with safety, civil and industrial engineering published 717, 10.5\% of documents. Majority research 6296, 92.3\% documented in the English language, meanwhile remaining 525, 7.6\% attract more 32 languages and show there richness in scientific vocabulary. This study explains the determinations of researchers affiliated with a huge group of scientists attached to health and safety-related works in the construction industry around the globe. The caregivers in health and safety keen involve error-free environment for avoiding, reducing, and provision of the hazard-free arena to develop society.
\end{abstract}

KEY WORDS: BIBLIOMETRIC, HEALTH AND SAFETY, CIVIL ENGINEERING, MATERIAL SCIENCE AND CONSTRUCTION INDUSTRY.

\section{INTRODUCTION}

Working at heights, electric shocks, moving heavy loaded machinery, slip and trips, unawareness about the use of proper personal protective equipment (PPPE)

\section{ARTICLE INFORMATION}

Received 27th Oct 2020 Accepted after revision 19th Dec 2020 Print ISSN: 0974-6455 Online ISSN: 2321-4007 CODEN: BBRCBA

Thomson Reuters ISI Web of Science Clarivate Analytics USA and Crossref Indexed Journal

\section{Clarivate
Analytics}

NAAS Journal Score 2020 (4.31)

A Society of Science and Nature Publication,

Bhopal India 2020. All rights reserved.

Online Contents Available at: http//www.bbrc.in/

Doi: http://dx.doi.org/10.21786/bbrc/13.15/7 and poor working conditions are the mixed appearances of health and safety in construction industry. 1 Fall from height (FFH) is emerging research areas in the construction industries, in context; computer and information technology tools help evaluate existing safety management programs in prevention of damages and losses. 2 All construction projects carry some level of risk. Which needs to identify and managed through skills, careful planning, and being able to make good decisions promptly. 3 A truly effective health \& safety management system establishes and maintains a culture of safety that permeates the entire organization. Ensuring safety on construction sites is major contest in terms of management commitment with meeting deadlines

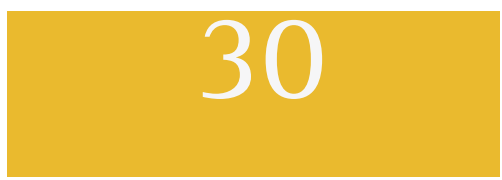


between work related accidents and work-related diseases. 4 Health and safety management are essential in the construction and installation areas for enterprise sustainability, employee health and social stability. 5 The potential harm to workers, a serious accident can cause work to stopped or delayed and lead to a decrease in productivity due to low morale. 6 Notwithstanding association size or type, the best wellbeing and security the executives frameworks apply a good judgment approach dependent on an exhaustive comprehension of the particular dangers and dangers the organization faces day by day. 7 .

Recently, a study conducted on Web of Science (WoS) to check rapid growth of literature on progress and evolving trends on employee sickness absence, safety performance and the relationship between safety culture/atmosphere. Study categorize 4,852 research documents mainly on industrial environment, occupational health care and covering business management, medicine, psychology and safety sciences published between 1900 and 2018. 8 A research similar above, on topic of human reliability in the Web of Science Core Collection (WOSCC) database between the years 2000 - 2019. Study evaluates 117 out of 198 documents existing on journal articles and conference papers, under the two criteria, a) monitoring health and safety of workers on construction sites, and b) integrated techniques of computer vision. This study suggests the usage of computer vision techniques helps to improve psychological state of employee in progress of workability and prevent occupational health diseases and accidents. 9 This is also interesting that, how bibliometric studies are helpful to know to make chemical industry of China more sustainable through the progress and shortcomings in current research in safety as basis from 1955 - 2019.

Web of Science Core Collection (WOSCC) database support to retrieved 1285 out of 2996 publications limiting the affiliation of country. 10 In 2019, an assessment conducted on 513 research articles, which published in Scopus-Elsevier Database based indexed journals in the area of construction safety. This study reveals that a variety of topics related to management in simulation and fall from height in recent past get attention in developing countries. 11 Same year, Zhao pointed another angle of studies and studied 2980 articles published from 2000 - 2016 with a bibliometric approach, to analyze subject categories of green building technologies in construction process. 12 Before Zhao, an observational study conducted on the research productivity of the Pakistan Journal of Science and Industrial Research (PJSIR) from 1957 - 2007. This study expressed that 4929 articles published during the studied period in 340 issues, with the caption of physical, biological and technological sciences. 13 An interesting study explains that Nordic country; Netherlands, Italy, and the United Kingdom frequently performed bibliometric methodological studies on the Web of Science (WoS) database, to observed and assess the growth of publications, subject domain, authorship pattern, influential institutes, and research performance. 14 .

\section{MATERIAL AND METHODS}

The research data in Health and Safety in Construction published in the journals indexed in Scopus-Elsevier Database from 1964 to 31 December 2019, downloaded on the date June 6, 2020, for tabulations in MS Office Excel Sheet 2010. The file format with comma-separated value (CSV) and Abstract on Note-paid techniques used, typed "Health and Safety in Construction", in the Boolean operator AND appears by default. To calculate year-wise publications, b) to identify document type, c) to estimate the position of authors, d) to calculate the institutional participation in research, e) to evaluate the association of topic with subject specialties, f) to check the involvement of countries in publications, g) to analysis language pattern with keywords of publications were set to explore as objectives.

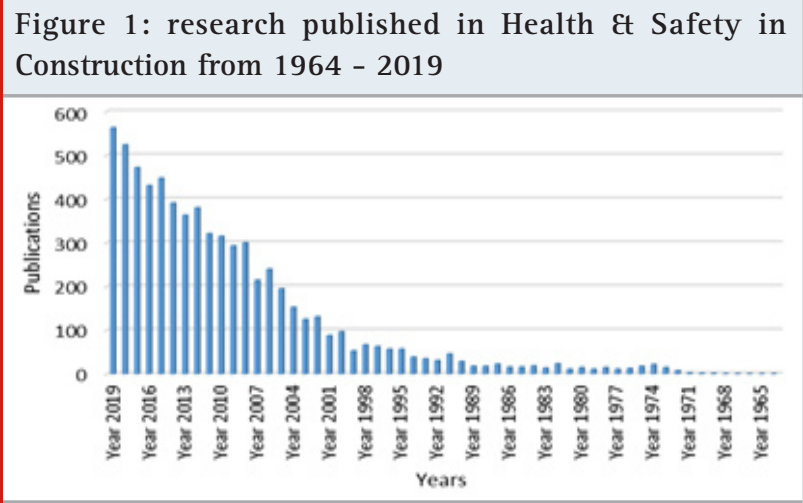

Table 1. Document Type

\begin{tabular}{|l|c|c|c|}
\hline S. No & Document Type & Publication & $\%$ \\
\hline 1 & Article & 4042 & $59.26 \%$ \\
\hline 2 & Conference Paper & 1890 & $27.71 \%$ \\
\hline 3 & Review & 467 & $6.85 \%$ \\
\hline 4 & Book Chapter & 124 & $1.82 \%$ \\
\hline 5 & Conference Review & 78 & $1.14 \%$ \\
\hline 6 & Short Survey & 63 & $0.92 \%$ \\
\hline 7 & Book & 51 & $0.75 \%$ \\
\hline 8 & Note & 45 & $0.66 \%$ \\
\hline 9 & Letter & 14 & $0.21 \%$ \\
\hline 10 & Editorial & 13 & $0.19 \%$ \\
\hline 11 & Business Article & 10 & $0.15 \%$ \\
\hline 12 & Report & 7 & $0.10 \%$ \\
\hline 13 & Abstract Report & 5 & $0.07 \%$ \\
\hline 14 & Data Paper & 2 & $0.03 \%$ \\
\hline 15 & Erratum & 2 & $0.03 \%$ \\
\hline 16 & Retracted & 1 & $0.01 \%$ \\
\hline 17 & Undefined & 7 & $0.10 \%$ \\
& & & Total \\
& & & documents 6821 \\
\hline
\end{tabular}




\section{RESULTS}

Figure 1, shows that, 6821 with an annual average of 121.8 documents written by 43,375 authors and with an average of 15.7 authors participated published documents, maximum 563 and minimum 1 research were included yearly and through-out from year 2002 this study found incline position of publications from the $1964-2019$.

Table 1 reveals that, the information of 6821 publications divided in seventeen sections were extract from the Scopus databases, the majority 4042, 59.2\% research existing on research "Articles" followed by 1890, 27.7 Conference papers and 467, 6.8\% Review Articles. The extract data of study reveals 28 subject areas, but we divided into four main catagories due to requirement and sentimentality of the study. Table 2 , shows the influnces of material sciences in hierarchy of subjects.

Table 2. Subject Areas of Health and Safety in Construction $1964-2019$

\begin{tabular}{|c|c|c|c|}
\hline S. No & Subject Areas & Publications & $\%$ \\
\hline 1 & $\begin{array}{c}\text { Engineering \& Applied } \\
\text { Engineering Sciences }\end{array}$ & 3524 & $51.6 \%$ \\
\hline 2 & $\begin{array}{c}\text { Medicine \& Health } \\
\text { Sciences }\end{array}$ & 2162 & $31.7 \%$ \\
\hline 3 & $\begin{array}{c}\text { Mathematics \& } \\
\text { Computer Sciences }\end{array}$ & 743 & $10.8 \%$ \\
\hline 4 & $\begin{array}{c}\text { Earth and Planetary } \\
\text { Sciences }\end{array}$ & 392 & $5.7 \%$ \\
\hline & Total documents 6821 & & \\
\hline
\end{tabular}

Table 3 \&t Figure 2, categorized authors into twenty-five basic lots to understand the nomenclature of document producers. The first twelve rows reflect the name of contributors in productivity as solo or as participators and second thirteen rows showing the positions of documents written by authors collaboratively. Total 1735 multiple by 25 groups resulted, study found 43,375 authors. Then the ratio of 15.7 authors wrote 6821 documents. Lingard, $\mathrm{H}$. took a high position with 51, 0.75\% followed by Smallwood, J. 33, 0.48\% and Anon and Gibb, A. with 29, 0.43\% article published out of 6821 articles.

The data of the study pointed-out only the names of 160 institutes which contributed as a minimum 10 and maximum of 145 articles in publishing from $1964-2019$. Figure 3, shows the name of institutes with participation of publications. The National Institute for Occupational Safety and Health, Cincinnati, Ohio United States of America with $145,2.1 \%$ ahead in publications and followed by Loughborough University, United Kingdome 98, 1.4\%, RMIT University, Australia 79, 1.16\% and Hong Kong Polytechnic University, China 78, 1.14\%.
Figure 4, reveals globally participation in the research productivity. United States of America put its input with 1928, 34\% articles followed by United Kingdome, People Republic of China, Australia, Canada, Italy, Germany, India and Brazil.

Table 3. Breakdown of contributed authors in documents

\begin{tabular}{|c|c|c|c|}
\hline S. No & Authors & Documents & $\%$ \\
\hline 1 & Lingard, H. & 51 & $0.12 \%$ \\
\hline 2 & Smallwood, J. & 33 & $0.08 \%$ \\
\hline 3 & Anon & 29 & $0.07 \%$ \\
\hline 4 & Gibb, A. & 29 & $0.07 \%$ \\
\hline 5 & Chan, A.P.C. & 28 & $0.06 \%$ \\
\hline 6 & Lipscomb, H.J. & 24 & $0.06 \%$ \\
\hline 7 & Blismas, N. & 22 & $0.05 \%$ \\
\hline 8 & Gibb, A.G.F. & 21 & $0.05 \%$ \\
\hline 9 & Edwards, D.J. & 20 & $0.05 \%$ \\
\hline 10 & Li, H. & 19 & $0.04 \%$ \\
\hline 11 & Smallwood, J.J. & 19 & $0.04 \%$ \\
\hline 12 & Gambatese, J.A. & 18 & $0.04 \%$ \\
\hline 13 & 2 Authors wrote 16 articles & 32 & $0.07 \%$ \\
\hline 14 & 3 Authors wrote 15 articles & 45 & $0.10 \%$ \\
\hline 15 & 2 Authors wrote 14 articles & 28 & $0.06 \%$ \\
\hline 16 & 5 Authors wrote 13 articles & 65 & $0.15 \%$ \\
\hline 17 & 7 Authors wrote 12 articles & 84 & $0.19 \%$ \\
\hline 18 & 7 Authors wrote 11 articles & 77 & $0.18 \%$ \\
\hline 19 & 10 Authors wrote 10 articles & 100 & $0.23 \%$ \\
\hline 20 & 15 Authors wrote 9 articles & 135 & $0.31 \%$ \\
\hline 21 & 19 Authors wrote 8 articles & 152 & $0.35 \%$ \\
\hline 22 & 18 Authors wrote 7 articles & 126 & $0.29 \%$ \\
\hline 23 & 38 Authors wrote 6 articles & 228 & $0.53 \%$ \\
\hline 24 & 21 Authors wrote 5 articles & 105 & $0.24 \%$ \\
\hline 25 & $\begin{array}{l}\text { Unidentified authors } \\
\text { wrote } 245 \text { articles } \\
25 \text { X } 1735=43375\end{array}$ & $\begin{array}{l}245 \\
1735\end{array}$ & $0.56 \%$ \\
\hline & $\begin{array}{c}6821 \div 43375 X \\
100=15.7 \text { authors }\end{array}$ & 43375 & \\
\hline
\end{tabular}

Figure 2: Contribution of authors in publications from $1964-2019$

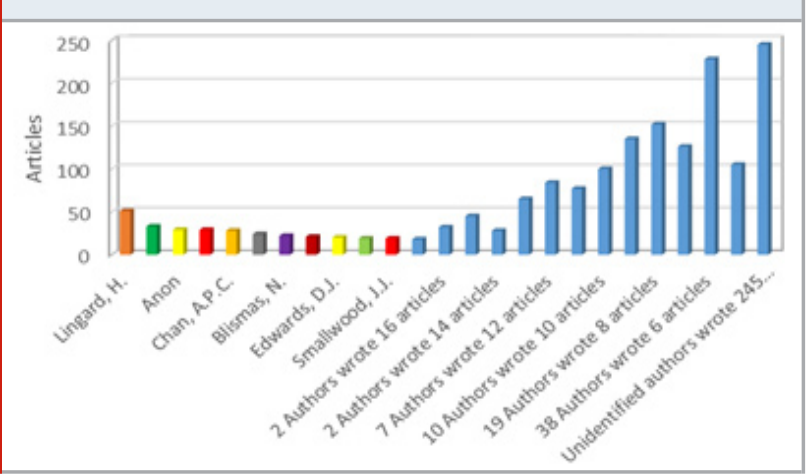


Word is a single unit of spoken language. A word always symbolizes the main idea of thinking, sharing experiences, or feature concepts of plans, stories, decisions, signs, and emotions. Table 5 shows the usage of 160 different individual or compound words as word, keywords utilized in 6821 documents, which enriched the research content. The Finnish, Korean, and Lithuanian languages contributed 3, 0.04\% articles, Arabic, Danish and Hungarian with 2, 0.03\% articles and Bosnian, Bulgarian, Greek, Hebrew, Latvian, Malay, Norwegian, Romanian, Serbian, Slovenian, Swedish and Ukrainian languages participated with one $0.01 \%$ article.

Figure 3: The contribution of top 15 Institutes in research published from 1964 - 2019

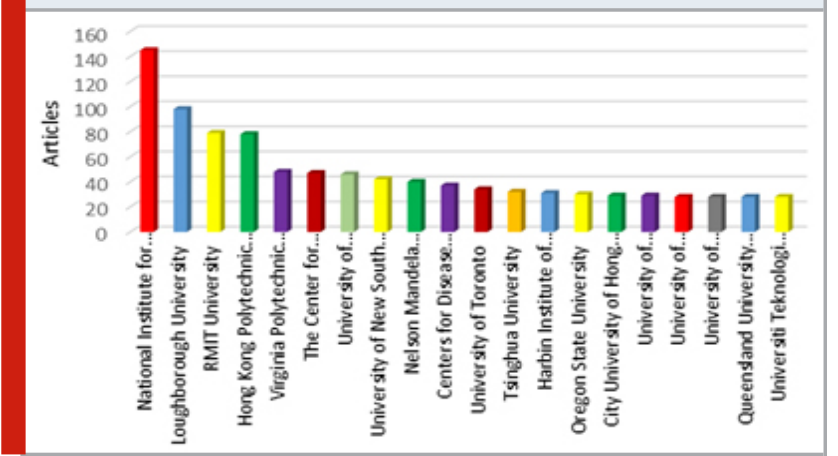

\section{DISCUSSION AND CONCLUSION}

The various types of documents published during the period of 1964 - 2019, this study download 6821 articles. The studied period can be distributed in four eras i.e first cluster 1964 - 1977 published 99, 1.4\%, second group 1978 - 1993 published 275, 4\%, third span 1994 - 2005 published 1191, 17.4\%, and fourth era 2006 - 2019 published 5256, 77\% documents out of 6821 documents. This study can assume that the changes in postal and traditions in information communication technology strongly effect the style of dispatching and reviewing of manuscripts to publish the ideas, and experiences of researchers in collaborative manners.

The research data of study merged sub-specialties into the main specialty with creations of four main classes to easy understanding of concerned topic. The spectrum of topic involves every corner of information from chalking the plans of project infrastructure, presenting it on surface with physical resources, covering-up with financial resources, designing, assigning the responsibilities, getting observations, analysis, findings and suggestions in form of reporting. Receiving every bit of information from human resources is a significant opportunity or threat to personals of construction industry for maintaining guidelines, standards to deal in health and safety. The fourth decade covers the huge amount of research, applying the guidelines and standards of health and safety in construction work, consequently receiving the results of success or damaging the assets with lives of human beings. These scenarios push planners to rethink,
Figure 4: The contribution of top 20 countries in research from $1964-2019$

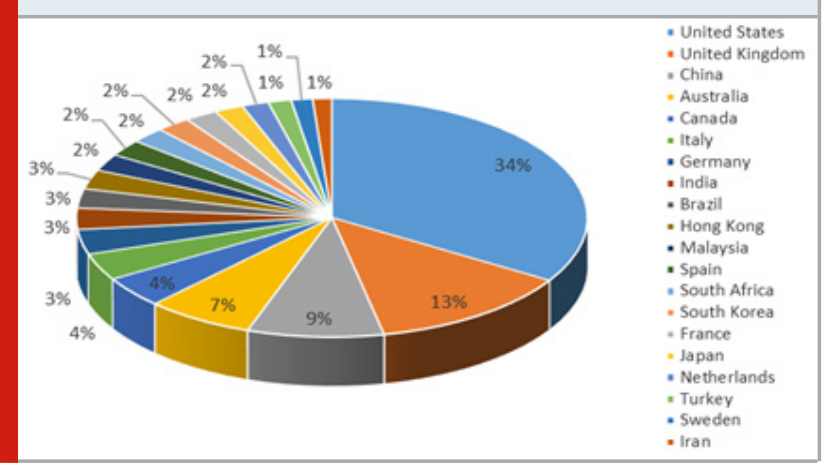

Table 4. The usage of key-words and languages in research published from 1964 - 2019

\begin{tabular}{|c|c|c|c|c|c|}
\hline S. No & Key-words & Words & Language & Articles & $\%$ \\
\hline 1 & Human & 2048 & English & 6296 & $92.30 \%$ \\
\hline 2 & Article & 1586 & Chinese & 101 & $1.48 \%$ \\
\hline 3 & Humans & 1582 & German & 90 & $1.32 \%$ \\
\hline 4 & $\begin{array}{c}\text { Construction } \\
\text { Industry }\end{array}$ & 1452 & Italian & 71 & $1.04 \%$ \\
\hline 5 & Safety & 1116 & Spanish & 52 & $0.76 \%$ \\
\hline 6 & $\begin{array}{c}\text { Accident } \\
\text { Prevention }\end{array}$ & 939 & French & 46 & $0.67 \%$ \\
\hline 7 & $\begin{array}{c}\text { Occupational } \\
\text { Health }\end{array}$ & 775 & Portuguese & 40 & $0.59 \%$ \\
\hline 8 & $\begin{array}{c}\text { Occupational } \\
\text { Risks }\end{array}$ & 763 & Russian & 40 & $0.59 \%$ \\
\hline 9 & $\begin{array}{c}\text { Risk } \\
\text { Assessment }\end{array}$ & 724 & Persian & 16 & $0.23 \%$ \\
\hline 10 & Male & 662 & Polish & 11 & $0.16 \%$ \\
\hline 11 & Adult & 651 & Japanese & 9 & $0.13 \%$ \\
\hline 12 & $\begin{array}{c}\text { Health And } \\
\text { Safety }\end{array}$ & 629 & Dutch & 7 & $0.10 \%$ \\
\hline 13 & United States & 588 & Czech & 6 & $0.09 \%$ \\
\hline 14 & Health & 585 & Turkish & 5 & $0.07 \%$ \\
\hline 15 & Female & 576 & Croatian & 4 & $0.06 \%$ \\
\hline
\end{tabular}

remap, reconsider and research the new horizons without any errors.

This study reveals the missionary movements of health and safety caretakers in construction industries; their observations support to evaluate the policies, modification and redesigning of measures, to deal sensitivity of clear danger, avoiding the culture of losses of every asset from any hazard. The interesting part of this study is the usage of 160 different words as single or compound in keywords. Human, Humans, Articles, Safety and Construction Industry are the words used as keywords in most of the articles published in studied period. The topic of health and safety in construction industry grab the attention of the researchers of 33 
languages around the world. Twelve languages of different countries present one article, nine articles published in other three languages, and the majority of 6296, 92.3\% articles published in the English language followed by Chinese, German, Italian, Spanish, French, Portuguese and Russian minimum 10 to maximum 101 articles out of 6821 articles.

The organization's performance measured against agreed standards to reveal when and where improvement needed. Active self-monitoring reveals how effectively the safety and health management system is functioning. 15 Self-checking takes a gander at both equipment (premises, plant and substances) and programming (individuals, strategies and frameworks, including singular conduct and execution). On the off chance that controls come up short, receptive observing should discover why they fizzled, by examining the mishaps, sick wellbeing or occurrences, which could have caused damage or misfortune. 16 Keeping workers safe should be the top priority of every company, the potential harm to workers, and a serious accident can cause work be stopped or delayed. The high levels of ill health, accidents and injuries within construction workers explained by a high variety of risk factors at the workplace. 17

Authors' Contributions: Dr. Abdullah Alabdali programmed this bibliometric research for this study, collected data from Scopus-Elsevier Database from 1964 to 31 December 2019 Indexed Journals for statistical analysis and reviewed. Author read and approved the final manuscript.

Disclaimer: This data published in Scopus-Elsevier Database from 1964 to 31 December 2019 Indexed Journals; it supports only participation and not inclined or declined of any organization, city, country, and standards.

Conflict of Interest: None to declare.

Funding Disclosure: None to declare

\section{REFERENCES}

Baladi, Zameer Hussain. "Special Paper A Bibliometric Portrait of Pakistan Journal of Scientific and Industrial Research (PJSIR) During the Period of 1958-2007.” Pakistan Journal of Scientific \& Industrial Research Series A: Physical Sciences 61, no. 3 (2018): 121-125. https://v2.pjsir.org/index.php/biological-sciences/ article/view/360

Di Donato, Michael F., Ross Iles, Tyler J. Lane, Rachelle Buchbinder, and Alex Collie. "The Impact of Income Support Systems on Healthcare Quality and Functional Capacity in Workers with Low Back Pain: A Realist Review." medRxiv (2020). doi: https://doi. org/10.1101/2020.01.13.20017343

Fuller, Colin W. "An employee-management consensus approach to continuous improvement in safety management.” Employee Relations (1999). https://doi. org/10.1108/01425459910285528

Grytnes, Regine, Dylan E. Tutt, and Lars Peter Sønderbo Andersen. "Developing safety cooperation in construction: between facilitating independence and tightening the grip." Construction Management and Economics (2020): 1-16. https://doi.org/10.1080/0144 6193.2020.1726978

Jappe, Arlette. "Professional standards in bibliometric research evaluation? A meta-evaluation of European assessment practice 2005-2019." PloS one 15, no. 4 (2020): e0231735. https://doi.org/ 10.1371/journal. pone.0231735

Jin, Ruoyu, Patrick XW Zou, Poorang Piroozfar, Hannah Wood, Yang Yang, Libo Yan, and Yu Han. ”A science mapping approach based review of construction safety research." Safety science 113 (2019): 285-297. https:// doi.org/10.1016/j.ssci.2018.12.006

Liu, Zepeng, and Long Zhang. "A review of failure modes, condition monitoring and fault diagnosis methods for large-scale wind turbine bearings." Measurement 149 (2020): 107002. https://doi. org/10.1016/j.measurement.2019.107002

Perry, J. G., and R. W. Hayes. "Risk and its management in construction projects." Proceedings of the Institution of Civil Engineers 78, no. 3 (1985): 499-521. https://www. icevirtuallibrary.com/doi/abs/10.1680/iicep.1985.859 Tao, Jing, Dongyang Qiu, Fuqiang Yang, and Zaipeng Duan. "A bibliometric analysis of human reliability research." Journal of Cleaner Production (2020): 121041. https://doi.org/10.1016/j.jclepro.2020.121041

Veil, Shari R., Kathryn E. Anthony, Timothy L. Sellnow, Nicole Staricek, Laura E. Young, and Pam Cupp. "Revisiting the best practices in risk and crisis communication: A multi-case analysis.” The Handbook of Applied Communication Research (2020): 377-396. https://doi.org/10.1002/9781119399926.ch23

Vigneshkumar, C., and Urmi Ravindra Salve. "A scientometric analysis and review of fall from height research in construction." Construction Economics and Building 20, no. 1 (2020): 17. https://doi.org/10.5130/ AJCEB.v20i1.6802

Vladkova, Blagovesta. "Best practices to improve construction site safety, in the specific conditions of processing plant building." In MATEC Web of Conferences, vol. 305, p. 00014. EDP Sciences, 2020. https://doi.org/10.1051/matecconf/202030500014

Wang, Bing, Chao Wu, Lang Huang, Liangguo Kang, and Yu Lei. "Safety science as a new discipline in China." Safety science 121 (2020): 201-214. https://doi. org/10.1016/j.ssci.2019.08.036

Wang, Yujie, Hong Chen, Bei Liu, Menghua Yang, and Qianyi Long. "A Systematic Review on the Research 
Progress and Evolving Trends of Occupational Health and Safety Management: A Bibliometric Analysis of Mapping Knowledge Domains." Frontiers in Public Health 8 (2020). https://doi.org/ 10.3389/ fpubh.2020.00081

Yang, Yunfeng, Guohua Chen, Genserik Reniers, and Floris Goerlandt. "A bibliometric analysis of process safety research in China: Understanding safety research progress as a basis for making China's chemical industry more sustainable.” Journal of Cleaner Production (2020): 121433. https://doi.org/10.1016/j.jclepro.2020.121433 Zhao, Xianbo, Jian Zuo, Guangdong $\mathrm{Wu}$, and Can Huang. "A bibliometric review of green building research 2000-2016." Architectural Science Review 62, no. 1 (2019): 74-88. https://doi.org/10.1080/00038628. 2018.1485548 